\title{
Cornell Announces Results of 2003 Materials Images Competition
}

Cornell University's Student Chapter of the Materials Research Society, in collaboration with the Department of Materials Science and Engineering (MS\&E), announced the results of its second annual Microscopy Image Competition: Images in the Material World. Three awards were given in each of two categories:

Most Scientifically Significant Image and Most Artistic Image. Prizes of digital cameras were provided by the Eastman Kodak Company.

The competition was promoted to undergraduate students in the United
States and Canada. Entries were judged by Cornell MS\&E professors Stephen Sass and Christopher Ober, who is also director of the department. More information on the contest is available at Web site www.mse.cornell.edu/imagescontest.
()

\section{Most Scientifically Significant Image} 1st Place

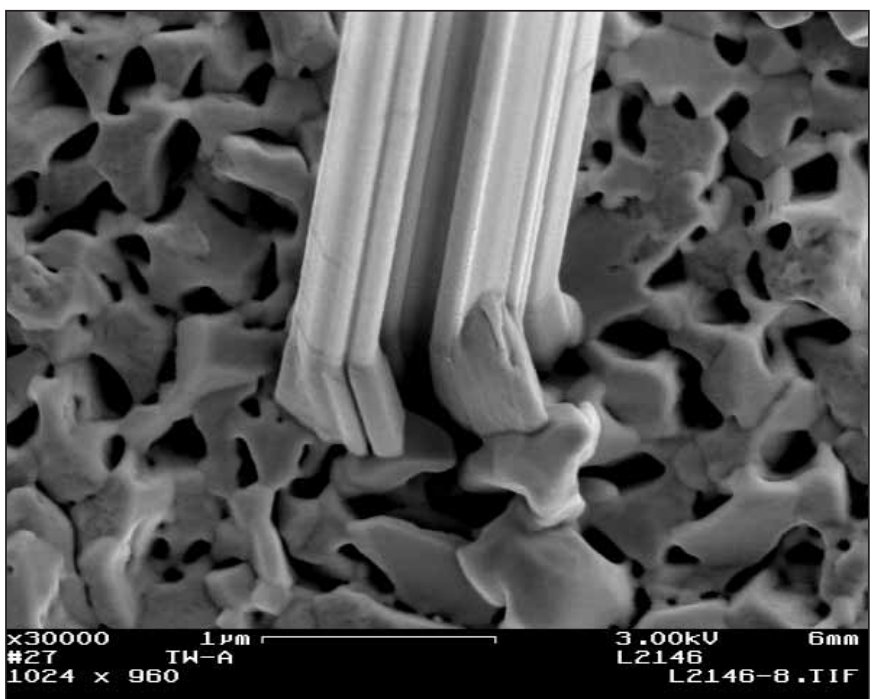

Tin Whisker

Joel LeBret, Washington State University

Imaging: Scanning Electron Microscope

Description: This SEM image of a tin whisker indicates the origin of striations or grooves on the surfaces of these long-time electronics hazards (i.e., when the tin whisker grows out at the surface, it acts like a wire creating a short-circuit in the electronics). The porous surface of the underlying tin grains directly produces the channels, which continue the entire length of the whisker.

\section{2nd Place}

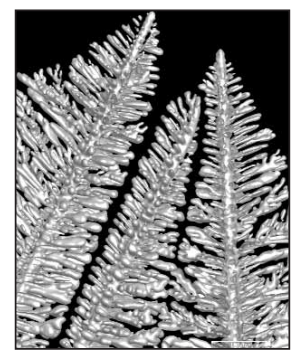

Higher-Order Dendritic Growth Erhan Altinoglu Northwestern University

Imaging: Optical Microscope Description: Reconstruction of aluminum dendrites based on 110 serial sections taken at $4.75 \mu \mathrm{m}$ intervals in an aluminum copper eutectic liquid. 3rd Place

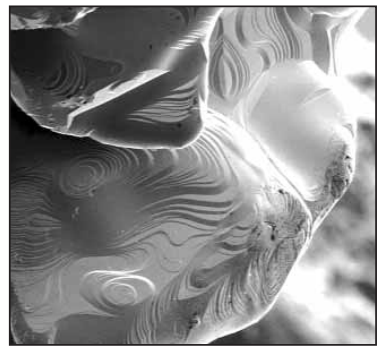

Etched Precious-Metal Alloy

Timothy Troutman

California Polytechnic State

University, San Luis Obispo

Imaging: Scanning Electron

Microscope

Description: Etched precious-

metal-alloy electrode designed to exhibit low polarization in stimulation and sensing (patent pending).
(2) Most Artistic Image 1st Place

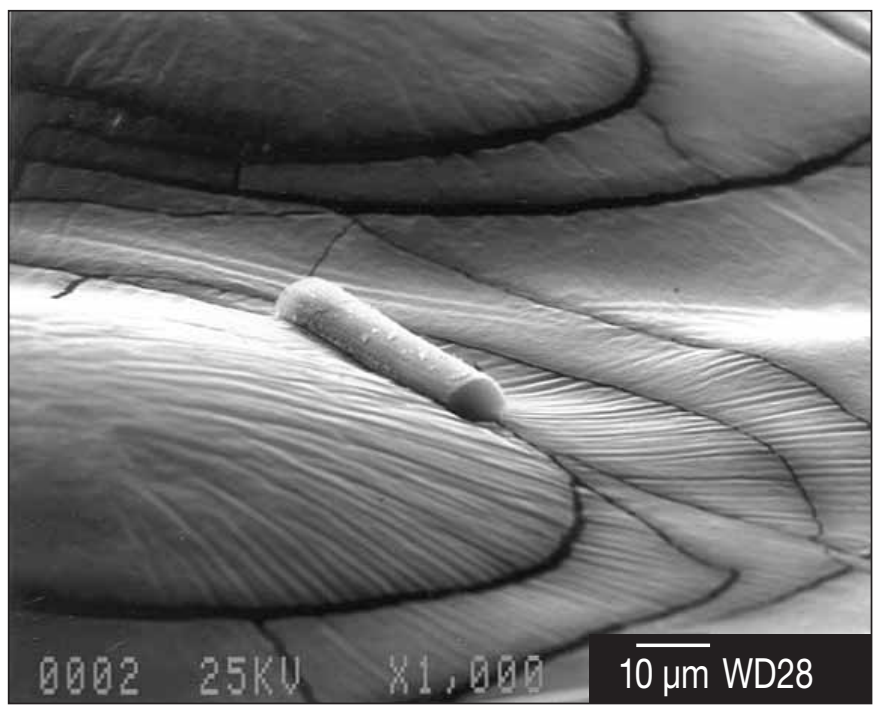

\section{Lone SiC-Coated Carbon Fiber}

Tatiana Russell, Rensselaer Polytechnic Institute

Imaging: Scanning Electron Microscope

Description: SEM image of a single SiC-coated carbon fiber on carbon mounting tape.

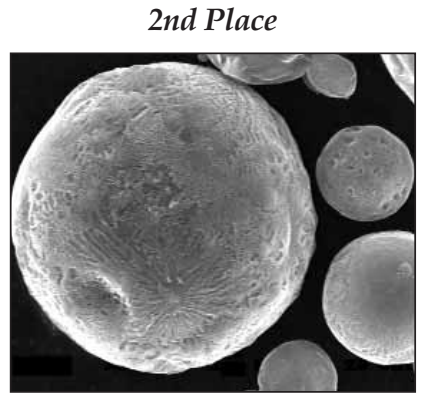

\section{Asteroids}

Amber Schneeweis

lowa State University

Imaging: Scanning Electron Microscope

Description: Atomized particles of $\mathrm{Al}-15 \mathrm{wt} \% \mathrm{Si}$ deeply etched in nitric/phosphoric acid to reveal the unique microstructures that form during rapid solidification.

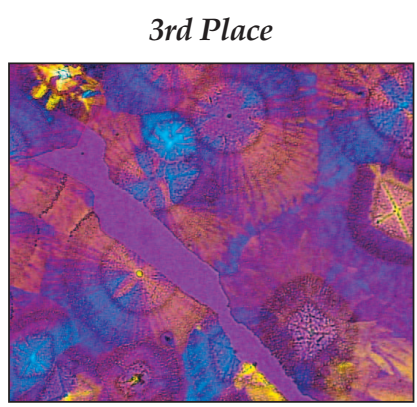

\section{Circles \& Squares}

Javier Gutierrez

University of Florida

Imaging: Polarized Light

Microscope

Description: Shape-retention of calcite crystals in $\mathrm{CaCO}_{3}$ film formation. 